\title{
Utilização de software livre para análise geoespacial - estudo de caso: seleção de área para instalação de aterro sanitário
}

Rodrigo Campi Sperb, Rafael Medeiros Sperb, Carlos Henrique Bughi, Luís Vinícius Mundstock Porto de Souza

\section{Resumo}

Este trabalho apresenta um estudo de caso envolvendo análise geoespacial complexa para identificação de áreas adequadas à instalação de aterro sanitário. Foram definidos os seguintes critérios técnicos: distância mínima de cursos d'água, distância mínima de vias, distância mínima e máxima de núcleos populacionais, tipo de solo e declividade do terreno. Para esta análise, foi empregado um SIG livre (opensource), com intuito não apenas de verificar a metodologia de análise, mas também assegurar a viabilidade deste tipo de ferramenta na prática. Os resultados indicam que a realização de tais processos de planejamento geoespacial com o uso de tecnologias livres, especialmente da utilizada no estudo de caso desenvolvido, é plenamente viável.

Palavras-chave: Planejamento geospacial; Planejamento ambiental; SIG open source; SIG livre.

Centro de Ciências Tecnológicas da Terra e do Mar - CTTMar Univ. do Vale do Itajaí - UNIVALI (rodrigosperb@univali.br).

Geosul, Florianópolis, v. 25, n. 49, p 159-177, jan./jul. 2010 
SPERB, R.C. et al. Utilização de sofware livre para análise geoespacial ...

Using free software to geospatial analysis -case study: seletion of area for sanitary landfill

\begin{abstract}
This article presents a case study involving complex geospatial analysis to identify proper areas for sanitary landfill installation. It has been defined the following technical criteria: minimum distance of streams, minimum distance of roads, minimum and maximum distance of urbanized areas, type of soil and terrain slope. To perform this analysis, it was employed a free GIS (opensource), intending not only to verify the analysis methodology, but also to assure the feasibility that kind of tool has on practice. Results have indicated that to perform such a process of geospatial planning using free technology, especially the one employed to the case study developed, is totally feasible.
\end{abstract}

Key words: Geospatial planning; Environmental planning; Opensource GIS, Free GIS.

\title{
Introdução
}

A necessidade de manutenção da qualidade ambiental em consonância com a crescente demanda por uso de recursos naturais por uma população também em expansão traz implicações que estão associadas a um espaço geográfico. Desta constatação emerge, cada vez mais presente, a aplicação de análises geoespaciais voltadas ao planejamento ambiental, como por exemplo, a seleção de áreas adequadas para implantação de aterro sanitário.

Historicamente, a coleta de informações sobre a distribuição geográfica dos mais diversos atributos (e.g. recursos minerais, propriedades, plantas e animais) sempre foi uma parte importante das sociedades organizadas (CÂMARA \& DAVIS, 2001). O acentuado crescimento da aplicação de Tecnologias de Informação, particularmente a partir da década de 1980, representou um grande avanço no sentido de permitir a combinação de diversos dados e informações, através de técnicas e análises de sobreposição (overlay). 
SPERB, R.C. et al. Utilização de sofware livre para análise geoespacial ...

Tais análises implicam na utilização de técnicas de geoprocessamento e no emprego de suas ferramentas computacionais, os Sistemas de Informações Geográficas (SIG). Estes permitem análises complexas, ao integrar dados de diversas fontes e ao criar bancos de dados georreferenciados, além de tornar possível automatizar a produção de documentos cartográficos (CÂMARA \& DAVIS, op cit.).

Atualmente, tem-se verificado um constante crescimento da penetração das técnicas de geoprocessamento nas organizações, a medida que os custos de hardware e software paulatinamente decrescem, e novas alternativas de construção de bases de dados geográficas surgem e tornam-se viáveis economicamente. Dentre as possibilidades de reduzir custos na aplicação de técnicas de geoprocessamento destaca-se a utilização de software livre, especialmente os de código aberto (opensource). Estes são programas de computador que, além de permitirem uso irrestrito e sem custos, oferecem ao usuário a possibilidade de acesso ao código fonte de programação do software (FSFeurope, 2007), e representam alternativas a sistemas comerciais, que embora consistentes, implicam em relativo alto custo, além de dependência de tecnologia proprietária.

Essa possibilidade de otimização econômica atrelada a um grau de independência, e de certa forma liberdade, que os sistemas baseados em software livre proporcionam vem sendo cada vez mais vista com bons olhos, nos mais diversos segmentos da sociedade. Câmara (2004) comenta que um marco histórico que denota esta tendência ocorreu em 2004, quando a cidade alemã de Munique selecionou o sistema operacional de código aberto Linux para os 14.000 computadores e servidores da Prefeitura, mesmo com a contraproposta da Microsoft igualando-se aos custos do ambiente de código aberto selecionado. $\mathrm{O}$ argumento foi que a Prefeitura não poderia depender de mais de uma tecnologia proprietária; esta mesma tendência passou a ser seguida paulatinamente por outros clientes. 
SPERB, R.C. et al. Utilização de sofware livre para análise geoespacial ...

Frente a esta perspectiva, o presente artigo discute a utilização de software livre para aplicação em análises geoespaciais, com ênfase em planejamento ambiental. Para tanto, optou-se por uma abordagem conceitual teórica acompanhada de um estudo de caso para verificar a aplicabilidade dessas soluções de baixo custo em projetos e estudos ambientais que envolvam o uso de sistemas de informações geográficas.

\section{Por que software livre?}

Atualmente, existe uma série de aplicações disponíveis para o livre uso e distribuição, sendo que algumas delas permitem ainda que os usuários aperfeiçoem sua funcionalidade (i.e. código aberto), em função de necessidades específicas dos mesmos. Entre elas estão bancos de dados, servidores de mapas para internet, bancos de dados geográficos, linguagens de programação, sistemas operacionais, entre outros (BOGORNY et al., 2002), além de aplicativos que executam funções de geoprocessamento, tais como as de sobreposição (overlay).

Abordando as perspectivas do Governo Federal para a utilização de software livre, Câmara (2004) avalia que é preciso considerar que a iniciativa de adotar sistemas de código aberto traz (a) redução de custo; (b) independência de tecnologia proprietária; e que existem (c) soluções de software livre eficientes e com boa qualidade; e (d) capacidade local de desenvolver soluções adaptadas para o cliente.

Basicamente, quatro características definem um software livre (de acordo com FSFeurope, 2007):

1. A liberdade de executar o programa para qualquer finalidade;

2. A liberdade de estudar como o programa funciona, e adaptar às suas necessidades (ou do cliente para quem se está desenvolvendo - Nota dos autores);

3. A liberdade de distribuir cópias; logo você pode ajudar seu vizinho; e 
SPERB, R.C. et al. Utilização de sofware livre para análise geoespacial ...

4. A liberdade de aperfeiçoar o programa; assim toda a comunidade de usuários se beneficia.

A maior parte dos analistas considera que o desenvolvimento descentralizado de código, o que ocorre em decorrência das características de software livre de código aberto, traz vantagens como o maior cuidado ao desenvolver o software, uma vez que o código fica à vista de todos (CÂMARA, 2004). Isto pode gerar maior qualidade e confiabilidade para a aplicação. Não obstante, essas vantagens não se restringem às boas intenções por parte dos desenvolvedores, que motivados por interesses não comerciais, ainda desenvolvem software de qualidade.

Com efeito, a tendência atual que se verifica é de crescimento no emprego de tecnologia livre, o que se denota também, pela constatação de que os desenvolvimentos dessas tecnologias não se encontram mais somente associados à iniciativas individuais ou de uma pequena equipe. Esta percepção contrasta com aquela visão original de "poucas cabeças pensantes" idealizando um software e de forma altruísta disponibilizando para livre uso, inclusive do código fonte.

Um argumento de suporte a essa constatação é fornecido pelos resultados da pesquisa realizada por Câmara (2004) para entender o mercado de desenvolvimento de software livre. Naquela ocasião, foi verificado que quase metade das tecnologias livres avaliadas estavam associadas a uma corporação. Nas palavras daquele autor, isto indica que "a grande força do desenvolvimento do software livre não são hackers altruístas que trabalham de madrugada, mas programadores profissionais cujo emprego é produzir software livre".

A maior confiança e qualidade que advêm do desenvolvimento de sistemas por corporações e suas equipes especializadas são potencializadas, eventualmente, pela interação usuário-desenvolvedor que é outra característica das tecnologias livres, em torno das quais costumam se desenvolver comunidades cooperativas. Nestas comunidades, é comum a colaboração dos tais hackers altruístas mencionados anteriormente, de forma a, numa 
SPERB, R.C. et al. Utilização de sofware livre para análise geoespacial ... situação idealizada, se gerar um fluxo contínuo de desenvolvimento/manutenção e aperfeiçoamento frente às necessidades específicas de usuários ou clientes. Tais aspectos colaboram de forma significante para a decisão de se utilizar software livre, especialmente os de código aberto, como alternativa para os mais diversos segmentos, como se verifica uma tendência nos dias de hoje.

\section{SIG livre - conceitos e evolução}

A grosso modo, um Sistema de Informação Geográfica pode ser definido como um sistema que permite manipular informação que está associada a uma referência geoespacial ou coordenadas geográficas. Em outras palavras, se a localização de uma certa informação é relevante, significa que, idealmente, dever ser armazenada/manipulada em ambiente SIG.

Rocha (2000 apud LAFIN, 2003) sintetiza os conceitos propostos por vários autores da área e define um SIG como:

Um sistema com capacidade para aquisição, armazenamento, tratamento, integração, processamento, recuperação, transformação, manipulação, modelagem, atualização, análise e exibição de informações digitais georreferenciadas, topologicamente estruturadas, associadas ou não a um banco de dados alfanuméricos.

Por conseqüência, um sistema de informação geográfica é considerado livre quando apresenta as características, ou pelo menos algumas delas, de um SIG e cumprem ainda os requisitos que definem uma tecnologia livre - i.e.: livres execução, cópia, distribuição, adaptação. Quando, além de livre uso e distribuição, é possível fazer aperfeiçoamentos via código diretamente por parte de usuários, trata-se de um SIG livre de código aberto.

Dentre os SIGs livres largamente utilizados, muito provavelmente o mais antigo e completo seja o GRASS (Geographic Resource Analysis Support System), desenvolvido originalmente por uma equipe do corpo de engenheiros do exército 
SPERB, R.C. et al. Utilização de sofware livre para análise geoespacial ...

dos Estados Unidos, em 1982. A formação de uma sólida comunidade de usuários, envolvendo um grande número de agências do governo americano, universidades, bem como a iniciativa privada, explica a grande disseminação desse software na área de análise geoespacial. Em decorrência disso, desde 1997 o código fonte do projeto é gerenciado por uma equipe internacional de desenvolvedores (GRASS Development Team).

No âmbito nacional, uma importante iniciativa em software livre voltado para análise geoespacial foi idealizada por uma equipe do Departamento de Processamento de Imagem do Instituto Nacional de Pesquisas Espaciais (DPI/INPE). O desenvolvimento do sistema SPRING se deu a partir de 1991 com o objetivo de atender as demandas brasileiras de monitoramento de recursos naturais e humanos (CÂMARA et al., 1996). Composto por funções de processamento de imagens, análise espacial, modelagem numérica de terreno e consulta a bancos de dados espaciais.

Embora dois softwares altamente confiáveis e de qualidade comprovada para análise geoespacial, cabe ressalvar que tanto o GRASS quanto o SPRING consistem em aplicações que demandam bom domínio inicial de técnicas e conceitos de geoprocessamento, e não apresentam interfaces tão "amigáveis" ou intuitivas, quando comparadas com soluções comerciais largamente difundidas. Estas características fazem com que o aprendizado nesses softwares muitas vezes torne-se laborioso para usuários inexperientes em SIG.

Somente mais recentemente, surgiram algumas iniciativas de desenvolvimento de SIGs de código aberto que se caracterizam por emprego de interfaces "amigáveis" para os usuários. Isto se deve, provavelmente, a constatação de que a manipulação de dados geográficos é uma realidade presente nos mais diversos segmentos da sociedade, e não se encontra restrita às necessidades de usuários altamente especializados em análise geoespacial.

Dentre essas iniciativas, destaca-se o gvSIG, que é uma ferramenta orientada para o gerenciamento de informação 
SPERB, R.C. et al. Utilização de sofware livre para análise geoespacial ...

geográfica com interface usuária "amigável", compatível com os mais usuais formatos vetoriais ou matriciais (raster), além de possibilitar tanto acesso local (i.e. arquivos armazenados localmente em computadores) quanto acesso remoto à bases disponibilizadas via Internet, por meio de serviços padronizados de interoperabilidade de dados. Uma discussão específica sobre esta ferramenta é apresentada a seguir.

\section{O aplicativo gvSIG}

O desenvolvimento do gvSIG teve seu início no final de 2003 quando Conselho Regional para Infra-estrutura e Transporte (CIT) do governo independente Valenciano, na Espanha, estabeleceu uma concorrência pública para o desenvolvimento de uma ferramenta de gerenciamento de informação geográfica que se caracterizasse por (GV/CIT, 2008):

- Portabilidade: pudesse ser executado independentemente da plataforma (inicialmente, Linux e Windows). Este aspecto é garantido pela utilização de linguagem de programação Java;

- Modularidade: permitisse o desenvolvimento de extensões com novas funções após o desenvolvimento concluído;

- Código aberto: o código de desenvolvimento original ficasse disponível;

- Desnecessidade de licença: após a conclusão do desenvolvimento, o aplicativo pudesse ser instalado sem necessidade de compra de licença alguma, independentemente da quantidade de instalações realizadas;

- Interoperabilidade com aplicações implementadas anteriormente: permitisse acesso a dados originados em softwares proprietários, como ArcView, Microstation, AutoCAD, sem precisar mudar o formato; 
SPERB, R.C. et al. Utilização de sofware livre para análise geoespacial ...

- Emprego de padrões: compreendesse a sujeição as especificações do Open Geospatial Consortium (OGC) e da União Européia.

O projeto gvSIG desenvolve-se de uma forma muito dinâmica, com constantes disponibilizações de novas funções implementadas, bem como distribuição freqüente do código fonte do software. O desenvolvimento pode ser acompanhado pelo sítio da Internet do projeto (http://www.gvsig.gva.es) que lista também as funções já implementadas, bem como aquelas que estão previstas no planejamento do software.

Além das funções implementadas especificamente pela equipe de desenvolvimento, o projeto gvSIG estabeleceu também uma parceria com outra ferramenta com funções de análise territorial do projeto Sextante (Sistema EXTremeño de ANalisis TErritorial), desenvolvido pela Universidade de Extremadura, Espanha. A integração deste último sistema no gvSIG adiciona mais de 170 funções de análise geoespacial implementadas principalmente para tratamento de informação geográfica em formato matricial (raster - i.e. dados contínuos que cobrem toda a superfície geográfica em análise), ao passo que o aplicativo original gvSIG tem seu foco em tratamento de informação geográfica em formato vetorial (i.e. pontos, linhas e polígonos).

De uma forma geral, todas as características elencadas acima indicam que o gvSIG se constitui de uma iniciativa relevante para aplicação em análises geoespaciais. Para verificar a aplicabilidade do emprego dessa ferramenta em planejamento ambiental, o presente trabalho é composto de um estudo de caso para seleção de área adequada para instalação de aterro sanitário, de acordo com critérios predefinidos e a execução de funções de análise de sobreposição em ambiente gvSIG. 
SPERB, R.C. et al. Utilização de sofware livre para análise geoespacial ...

\section{Estudo de caso - seleção de área para implantação de aterro sanitário}

\section{Considerações gerais}

A seleção criteriosa de área para implantação de aterro sanitário é crucial para a manutenção da qualidade ambiental de uma região, uma vez que não se pode escapar da necessidade desses empreendimentos no contexto contemporâneo. $\mathrm{O}$ conceito por trás dessa situação é o de que se gerar lixo é uma realidade que não se pode negligenciar, pelo menos que se faça sua disposição final de uma forma ambientalmente adequada.

Tal seleção criteriosa significa considerar aspectos que podem influenciar negativa ou positivamente a manutenção da qualidade dos ambientes das áreas disponíveis para instalação de aterro sanitário. A consideração desses aspectos parte do princípio que os terrenos apresentam características, naturais ou implantadas, que os fazem adequados ou não para a instalação de um empreendimento daquele tipo. Uma vez que avaliar essas questões implica em se considerar a distribuição geoespacial das variáveis interferentes, e como essas interagem no sistema ambiental em análise, o uso de SIG e técnicas de geoprocessamento constituem ferramenta indispensável de análise do problema.

\section{Modelo conceitual}

A seleção de área adequada para implantação de aterro sanitário em ambiente SIG se dá através de análises de sobreposição (overlay) que permitirão integrar as informações pertencentes as diferentes camadas - i.e. cartas temáticas com os critérios de análise. Conceitualmente, isto significa avaliar relações de pertinência, ou não, frente aos critérios considerados.

Na prática, o que se deve fazer é identificar terrenos em que não ocorrem características que os façam serem considerados como áreas de exclusão. Ao se identificar tais áreas, o primeiro passo para uma seleção criteriosa é alcançado: evitar-se aspectos que 
SPERB, R.C. et al. Utilização de sofware livre para análise geoespacial ...

podem influenciar negativamente na manutenção da qualidade ambiental da região.

O próximo passo é, finalmente, identificar, dentre as áreas passíveis de uso para aterro sanitário, em quais ocorrem aspectos que podem influenciar positivamente a manutenção da qualidade ambiental da região. Estas são áreas que atendem os critérios de inclusão.

O fluxograma abaixo sintetiza o modelo conceitual estruturado para resolver o problema de seleção de área para implantação de aterro sanitário com análises de sobreposição em SIG (Figura 1).

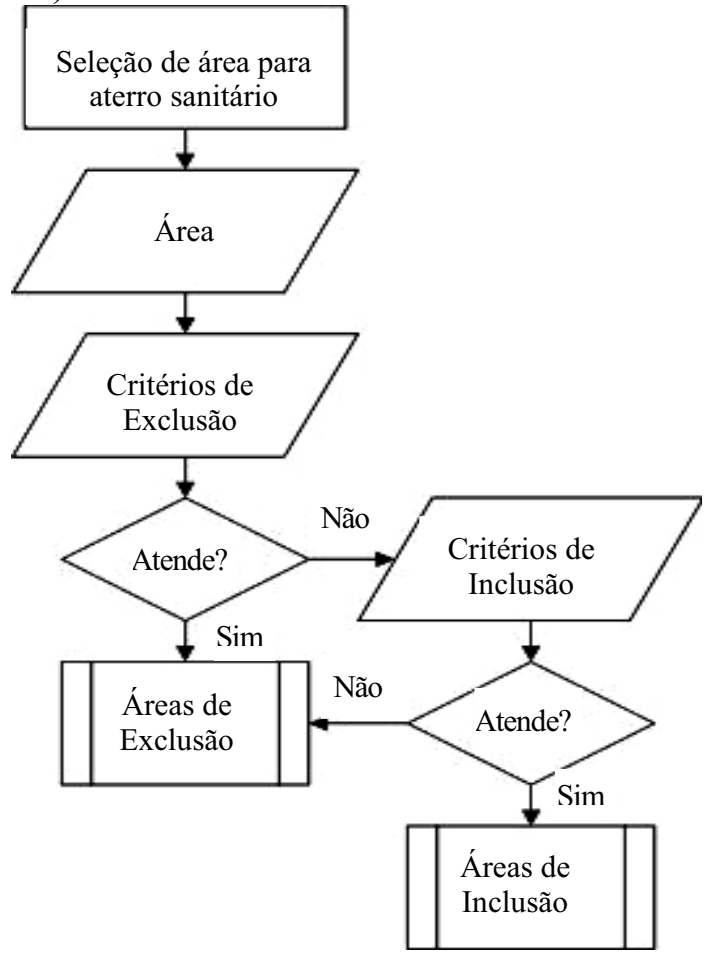

Figura 1: Fluxograma do modelo conceitual para resolução do problema de seleção de áreas para implantação de aterro sanitário. 
SPERB, R.C. et al. Utilização de sofware livre para análise geoespacial ...

\section{Definição do caso}

A área escolhida para o estudo de caso abrange os municípios de Itajaí, Itapema, Camboriú e Balneário Camboriú, no estado de Santa Catarina.

Delineou-se como objetivo para o caso em estudo a identificação de:

- Áreas adequadas para implantação de aterros sanitários em cada um dos 4 municípios de estudo;

- Áreas adequadas para implantação de aterro sanitário consorciado para os 4 municípios;

A instalação de aterros sanitários na forma de consórcios pode ser uma alternativa tanto para a eventual ausência de áreas disponíveis adequadas num certo município quanto para reduzir custos associados ao processo de disposição de resíduos sólidos. Por isso esta opção foi considerada neste estudo.

\section{Critérios de análise geoespacial}

Para selecionar as potenciais áreas de implantação de aterro sanitário, utilizou-se normas técnicas vigentes (ABNT NBR 13.896/97) para definir os critérios de exclusão de áreas (Tabela 1).

Tabela 1: Critérios de exclusão de áreas.

\begin{tabular}{lcc}
\hline \multicolumn{1}{c}{ Descrição } & Parâmetro & Critério \\
\hline Proximidade de cursos de água & $200 \mathrm{~m}$ & Distância mínima permitida \\
Proximidade de núcleos populacionais & $500 \mathrm{~m}$ & Distância mínima permitida \\
Proximidade de vias & $200 \mathrm{~m}$ & Distância mínima permitida \\
\hline
\end{tabular}

A definição de critérios de inclusão de áreas levou em conta aspectos tanto de ordem sócio-econômica quanto física dos terrenos. Os aspectos físicos considerados dizem respeito ao tipo de solo e a declividade da área. De uma forma geral, solos com boa profundidade e pouca permeabilidade é que são adequados para 
SPERB, R.C. et al. Utilização de sofware livre para análise geoespacial ...

implantação de aterros sanitários. Inclinação inferior à $30 \%$ também é um outro critério técnico para implantação desses empreendimento (cf. ABNT NBR 13.896/1997).

O critério de inclusão de ordem sócio-econômico consiste na otimização do transporte dos resíduos sólidos, o que implica em se considerar que o empreendimento não pode se encontrar muito distante dos núcleos populacionais mais significativos (i.e. em geral, área urbana dos municípios), tanto para o caso de aterros sanitários individuais para os municípios, quanto para o caso da solução consorciada.

Frente a essa duplicidade de soluções sendo avaliadas, estabeleceu-se que na análise de seleção de áreas individuais por município, estas não devem estar distante mais do que $7 \mathrm{~km}$ dos núcleos populacionais significativos, respeitada a distância mínima da área de exclusão. Já em relação a identificação de áreas adequadas para uma solução consorciada, definiu-se uma distância máxima de $15 \mathrm{~km}$ dos núcleos populacionais, em que pese a distância mínima da área de exclusão. Os critérios de distância foram considerados em termos de raio, não de distância percorrida em vias existentes.

\section{A análise geoespacial}

Ante aos critérios de análise definidos, foram necessárias informações geoespacializadas relativas a:

- Hidrografia (Fonte: Epagri/IBGE, 2004);

- Sistema viário (Fonte: Epagri/IBGE, 2004);

- Declividade (gerada a partir das curvas de nível - Fonte: Epagri/IBGE, 2004);

- Núcleos populacionais (Fonte: IBGE, 2001);

- Tipo de Solos (Fonte: IBGE, 2001)

As informações necessárias encontravam-se previamente armazenadas em arquivos SIG vetoriais, prontas para constituir um plano de informação para análise geoespacial no gvSIG. Com a utilização de consultas aos atributos (i.e. informações) associados 
SPERB, R.C. et al. Utilização de sofware livre para análise geoespacial ...

nas camadas de análise e aplicação de funções de proximidade (buffer) e sobreposição processou-se a identificação das áreas adequadas para implantação de aterro sanitário. O fluxograma abaixo (Figura 2) apresenta de forma didática a seqüência de procedimentos para a seleção das áreas que atendem os critérios estabelecidos.

Cabe ressaltar que no caso das áreas de exclusão, a ocorrência de qualquer um dos critérios de exclusão já caracteriza inadequação com critérios técnicos para seleção de áreas para implantação de aterro sanitário. Logo, a junção das camadas de buffer para formar as áreas de exclusão representa uma operação do tipo "ou espacial" (união), onde tanto as geometrias que ocorrem em mais de camada quanto aquelas que são exclusivas de uma ou outra camada constituem o conjunto final de dados.

Contrariamente, quando se trata das áreas de inclusão, faz-se necessária a ocorrência conjunta dos critérios. Isto caracteriza uma operação do tipo "e espacial" (intersecção), em que somente constituem o conjunto final as geometrias que atendem todos os critérios de uma forma convergente.

\section{Resultados da análise geoespacial}

A análise geoespacial realizada no gvSIG permitiu identificar áreas adequadas para implantação de aterro sanitário na área do estudo de caso, de acordo com os critérios de exclusão e inclusão de áreas definidos (ver Figura 2).

As áreas selecionadas considerando soluções de instalação de aterro sanitário individualizado por município podem ser observadas na Figura 3, ao passo que a solução consorciada (i.e. único aterro sanitário para os 4 municípios) pode ser verificada na Figura 4. 
SPERB, R.C. et al. Utilização de sofware livre para análise geoespacial ...

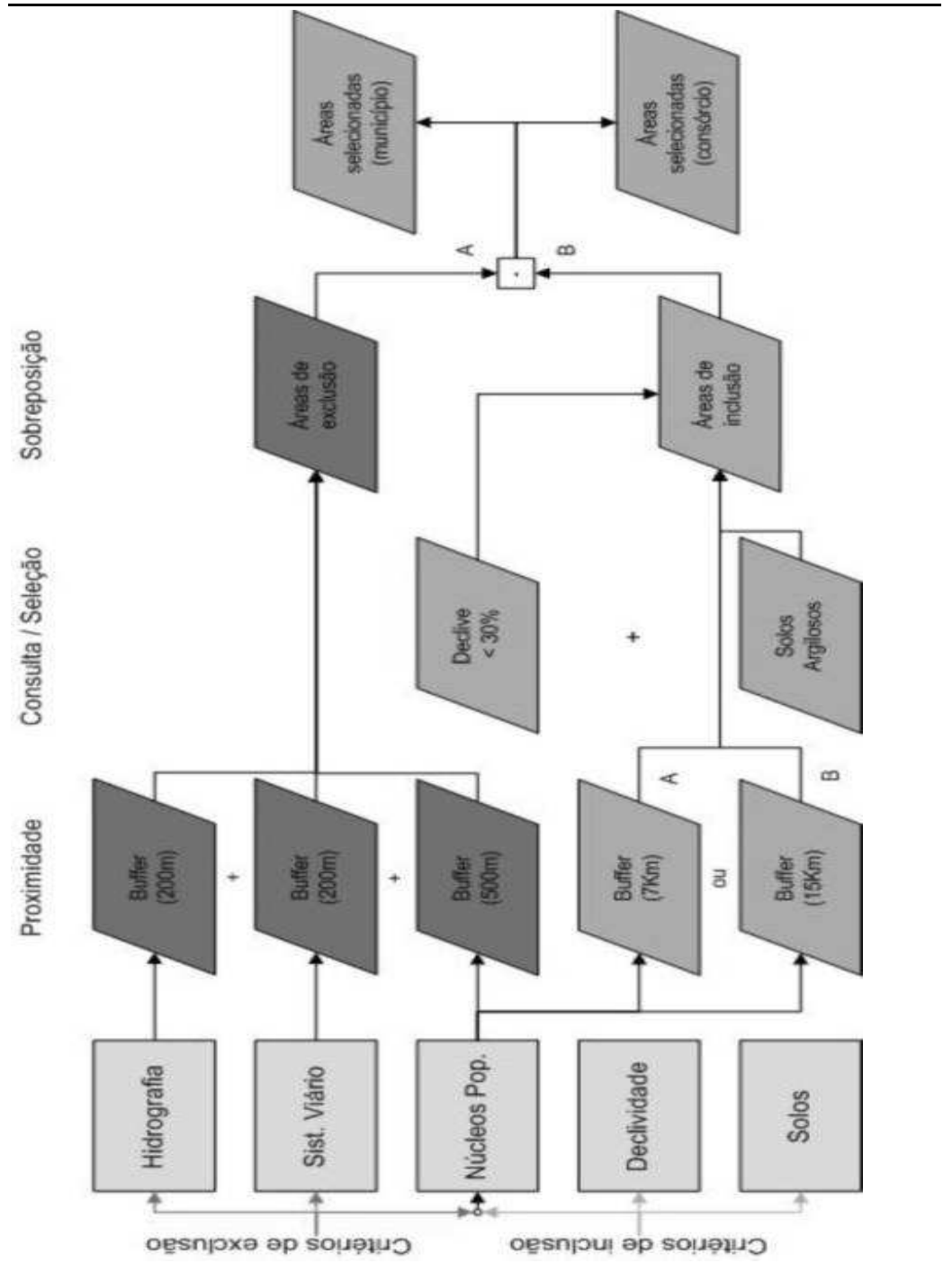

Figura 2: Fluxograma com os procedimentos para seleção de áreas adequadas para implantação de aterro sanitário em sig. 
SPERB, R.C. et al. Utilização de sofware livre para análise geoespacial ...

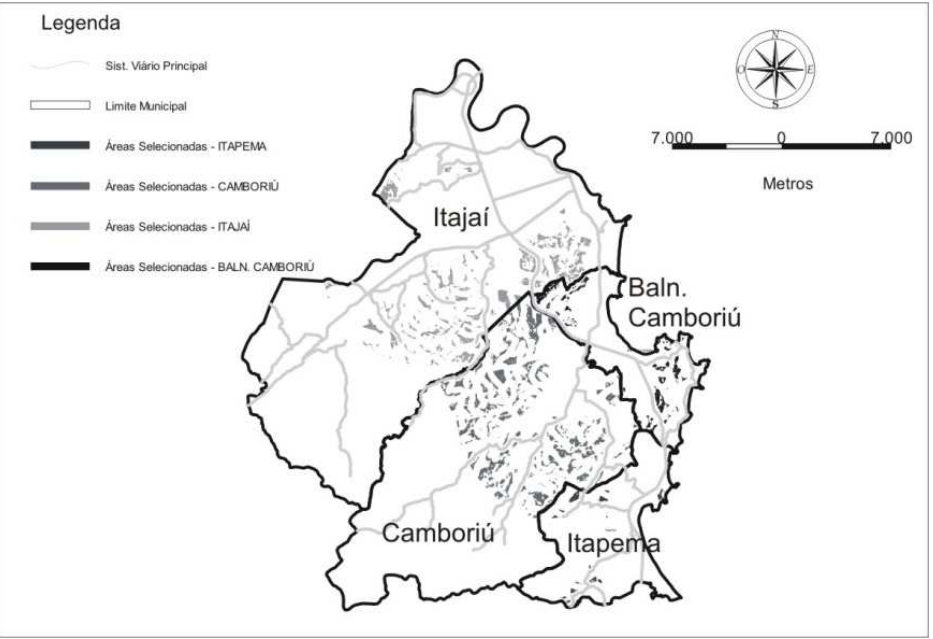

Figura 3: Localização das áreas selecionadas para implantação de aterro sanitário considerando solução por município.

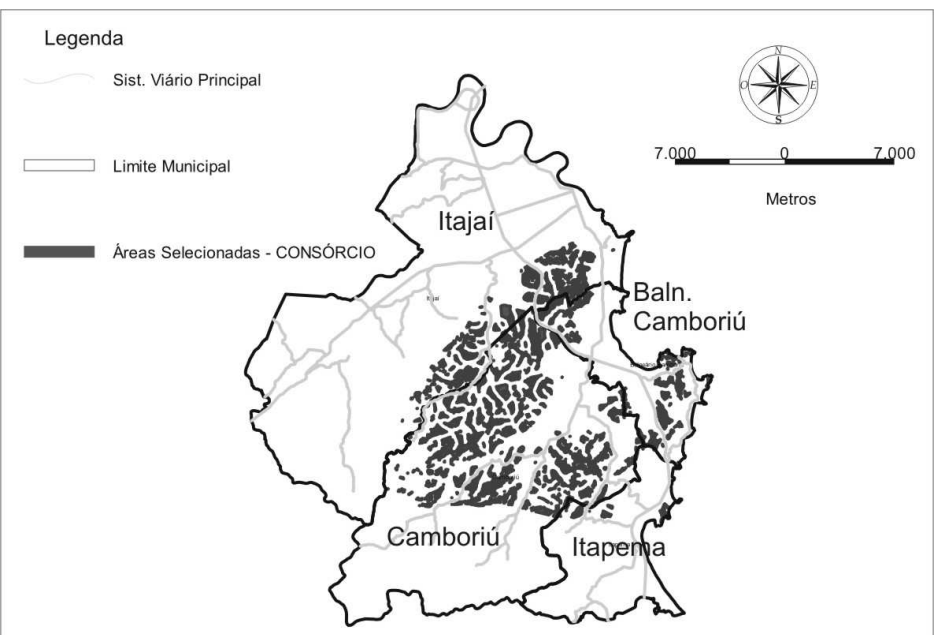

Figura 4: Localização das áreas selecionadas para implantação de aterro sanitário considerando a solução consorciada. 
SPERB, R.C. et al. Utilização de sofware livre para análise geoespacial ...

A Tabela 2 apresenta os resultados da análise geoespacial realizada para o estudo de caso em termos quantitativos. Os valores calculados indicam que há relativamente poucas áreas adequadas para implantação de aterro sanitário, frente aos critérios definidos, seja qual for o município da área de estudo avaliado.

Em média, 6,64\% das áreas dos municípios atendem os critérios definidos, sendo que o município de Camboriú é o que apresenta a maior superfície de terrenos adequados $(11,36 \%)$, enquanto o contrário ocorre com o município de Itapema, com menos de $2 \%$ de áreas selecionadas.

Esses resultados podem ser explicados, em parte, pela geomorfologia regional, que se caracteriza pela relevo movimentado, bem como pela dinâmica de ocupação de áreas, que privilegia as áreas mais planas. Esta última interfere no sentido de reduzir as áreas disponíveis para seleção com a ocorrência de núcleos populacionais em boa parte dos limitados terrenos planos.

Tabela 2: Resultados quantitativos da análise geoespacial.

\begin{tabular}{lccc}
\hline \multicolumn{1}{c}{ Município } & $\begin{array}{c}\text { Área (ha) - } \\
\text { selecionadas }\end{array}$ & $\begin{array}{c}\text { Área (ha) - } \\
\text { município }\end{array}$ & $\begin{array}{c}\text { Área (\%) - selecionadas } \\
\text { em relação ao município }\end{array}$ \\
\hline Itajaí & 1674,41 & 28864,46 & $5,80 \%$ \\
Baln. Camboriú & 346,55 & 4647,59 & $7,46 \%$ \\
Itapema & 114,17 & 5886,84 & $1,94 \%$ \\
Camboriú & 2417,67 & 21278,87 & $11,36 \%$ \\
\hline Consórcio & 3957,58 & 60677,76 & $6,52 \%$ \\
\hline
\end{tabular}

\section{Considerações finais}

Conforme discutido anteriormente, a utilização de software livre é uma alternativa que se tem mostrado viável em muitas situações, como menos custosa e que proporciona um grau de liberdade ao usuário quando comparado com os aplicativos comerciais. Com efeito, o estudo de caso avaliado neste trabalho demonstrou que é possível realizar análises geoespaciais de natureza complexa (i.e. englobando vários critérios, fatores), com o 
SPERB, R.C. et al. Utilização de sofware livre para análise geoespacial ...

uso de uma dessas ferramentas SIG livres disponíveis, no caso, o gvSIG.

Cabe ressaltar que a identificação dessas áreas adequadas para instalação de aterro sanitário com o uso de análise geoespacial em ambiente SIG se constitui numa importante ferramenta para os estudo prévios de seleção de área. Isto se deve ao fato de que é possível se direcionar quais áreas devem ser consideradas, frente aos critérios observados, em posteriores estudos mais aprofundados quando efetivamente se chegará a conclusão de qual a melhor localização para o empreendimento.

Finalmente, a viabilidade do uso de tecnologias livres para atividades de planejamento geoespacial/ambiental é particularmente importante num momento em que o Governo Federal exige das prefeituras a elaboração de Plano Diretor e Plano Municipal de Saneamento Ambiental, processos estes que demandam análises geoespaciais. Dessa forma, é possível desenvolver tais análises sem onerar financeiramente as prefeituras com a aquisição de soluções comerciais.

\section{Referências bibliográficas}

ASSOCIAÇÃO BRASILEIRA DE NORMAS TÉCNICAS. NBR 13896: Aterros de resíduos não perigosos - critérios para projeto, construção e operação. Rio de Janeiro, ABNT, 1997.

BOGORNY, V.; NIEVINSKI, F.; BIGOLIN, N.; CORRÊA, M.J. Desenvolvimento de um SIG para saúde pública usando software livre. In: Fórum Internacional de Software Livre. Porto Alegre, 2002.

CÂMARA, G. Software livre para GIS: entre o mito e a realidade. InfoGEO, v.31. 2004.

CÂMARA, G.; DAVIS, C. Cap 1: Introdução. In: Monteiro, A. M. V. et al. Introdução a Ciência da Geoinformação. São José dos Campos, SP: INPE, 2001. 
SPERB, R.C. et al. Utilização de sofware livre para análise geoespacial ...

CAMARA, G.; SOUZA, R.C.M.; FREITAS, U.M., GARRIDO, J. SPRING: Integrating remote sensing and GIS by object-oriented data modelling. Computers \& Graphics, v.20(3). 395-403, 1996.

EPAGRI/IBGE. Mapoteca Topográfica Digital de Santa Catarina. Empresa de Pesquisa Agropecuária e Extensão Rural do Estado de Santa Catarina/Instituto Brasileiro de Geografia e Estatística. 2004. Disponível em: <http://ciram.epagri.rctsc.br/ciram/produtos/geoprocessamento/mapoteca $>$.

FSFeurope - Free Software Foundation Europe. What is a free software?. 2007. Disponível em: <http://fsfeurope.org/documents/ freesoftware>. Acesso em: 13 fev 2008.

GV/CIT. gvSIG for windows, version 1.1. Generalitat Valenciana/Conselleria d'Infraestructures i Transport, 2008. Disponível em: $<$ http://www.gvsig.gva.es $>$.

IBGE - Instituto Brasileiro de Geografia e Estatística. Mapa Geomorfológico. Cartas SG-22-Z-B-V (folha Itajaí) e SG-22-Z-DII (folha Camboriú). Escala: 1:100.000. 2001.

LAFIN, N. A. Uso do Solo e Legislação Ambiental na Bacia do Rio Itajaí-Mirim, Santa Catarina: identificação das não conformidades, através de Sistemas de Informações Geográficas. Monografia de Graduação. UNIVALI. 2003.

Recebido em abril de 2008 Aceito em junho de 2009 
